\title{
A macro-analysis of quality assessment in higher education
}

\author{
EGBERT DE WEERT \\ Centre for Higher Education Policy Studies, University of Twente \\ P.O. Box 217, 7500 AE Enschede, The Netherlands
}

\begin{abstract}
In most West European countries a quality control system for higher education is in a process of development. This article examines some general characteristics of the emerging structures, how quality is defined and what impact this definition has on internal evaluation.

On the basis of a more substantive conceptualization of the term quality, the current trend of a quality control system in which quality is predominantly defined from one central power centre is questioned. Important methodological and substantive weaknesses inherent in this centralist model will be discussed.

In the final section a shift towards a quality control system is advocated in which other interests and perspectives are taken into account.
\end{abstract}

\section{Introduction ${ }^{1}$}

One of the current debates on the future of higher education veers between two alternative positions. On the one hand a higher education system, tightly controlled by the central government and on the other a market system in which competition amongst institutions and amongst students determines the structure of the system and the allocation of resources.

Adherents of the latter position place institutional autonomy at the heart of their strategy. The less institutions are subject to governmental control, the more they can be reactive to their external environments.

In this debate notions of "quality" and "performance" play a crucial role. Many national governments advocate more autonomy for institutions of higher education in order to operate more effectively with their environments and to enable them to meet new societal and industrial demands. Simultaneously, governments have stressed the need for accountability and quality improvement of higher education and are consequently embarking upon a quality control system. This growing concern with quality control is considered to be a logical consequence of a reduction of governmental interference in the internal matters of both the university and the non-university sector. In France, for example, president Mitterrand in 1985 launched his committee for the evaluation of universities with the words: "L'évaluation objective des forces et des faiblesses des universités est le contreparte même, normale, de leur autonomie" (Perry, 1987, 345).

Part of this autonomy is the acknowledgement that institutions of higher 
education themselves are primarily responsible for the quality of their education. Some commentators, however, have argued that the present emphasis upon a quality control system and the concerning legislation constitute a departure from all previous notions of institutional autonomy. For example, Neave has coined the term "conditional autonomy" to indicate that institutions are free to develop initiatives, courses and research "on condition that they have first reached the stipulated or expected level of, say, graduate student output, or can show staffing ratios to be within national norms, etc." (Neave, $1987,122)$. In this context the definition of what constitutes "quality" appears less to be defined internally by educational institutions themselves and more externally, either by the government or by the establishment of co-agencies.

This article deals with the tension between autonomy and external structures of quality control. In particular it attempts to give a theoretical account of the nature of the structures which currently emerge in several countries in Western Europe. Evidently, there are differences between countries, mainly due to historical and socio-political factors, which have to be taken into consideration. For example, differences with regard to the prevailing power structure within institutions and between institutions and the state. Or whether there exists a tradition with evaluation within the higher education system. Yet, from a macroperspective developments of external evaluation appear to be virtually interchangeable: the strengthening of the evaluation function by the government, the establishment of national evaluation committees, the inspectorate, the role of co-ordinating and planning bodies, as well as the search for quality standards and measures of institutional performance.

In what follows the validity of these emerging structures will be examined. How is "quality" defined, what consequences can be expected and to what extent will the operational characteristics have an impact on internally developed evaluation?

Such a discussion may contribute to a formulation of more feasible and more effective strategies orientated to the improvement of quality in higher education in any particular situation.

Before moving to this discussion the focus turns first to a discussion of the way the concept of quality can be conceived.

\section{A theoretical approach to quality}

It is remarkable that the increasing interest in enhancing quality in higher education has not kept pace with a better understanding of this concept. Quality has frequently been associated with the present need for more graduates in certain technological and natural sciences, or a greater efficiency and effectiveness as a consequence of governmental cutbacks. Policy documents 
mostly deal with questions concerning procedures, tasks and responsibilities of the respective agencies. Relatively little space is granted to a more substantive discussion of what quality of higher education is about.

Ball, chairman of the British National Advisory Body (NAB) for example, applauds the increasing tendency to bring quality judgments in the planning process. Yet, he hastens to say that to try and define what quality is, is one of the most difficult ventures we might undertake (Ball, 1985, 97). The Dutch Council of Higher Vocational Education, while presenting lately far-reaching measures to restructure health education, went so far as to say that these were not based on quality judgment, as the council did not feel competent to do this. If quality will play a role in the planning process and ultimately might lead to important decisions, the need for a better conceptualization of the term "quality" cannot be ignored.

One reason why the concept of quality is so difficult to grasp is that it is not possible to define it in a very straightforward way. As Pirsig $(1974,179)$ concludes, the concept is as elusive as it is pervasive. There are no clear-cut and single valued criteria or standards according to which quality can be measured. Not only does the assessment of quality of such an object like a work of art confront many professional critics with much difficulty, even the quality of an apple is subject to much disagreement: should it be juicy, sweet, unblemished? Other aspects are size, colour, consistency, storage-life, price and so on. No single characteristic will suffice and a final judgment is dependent on personal taste and on the purpose one has in mind.

A first view of the matter is a common-sense one. Quality in education can be defined in terms of the goals which are to be accomplished. Only by acknowledging that institutions of higher education are goal-directed can a secure basis for assessing quality be found. More precisely, an institution or an educational program is conceived to have quality, if complete goal fulfillment is attained, not just an acceptable amount. Furthermore, a conception of quality is not restricted to the outcome. Process and input factors should be included as well.

Process factors indicate the way the institution is attaining its goals. As Conrad and Blackburn note, quality carries with it "a dimension of style, not just an outstanding accomplishment but the manner in which the accomplishment is achieved"' $(1985,286)$.

Input factors usually refer to resources necessary for institutions to carry out their functions: financial, qualified staff, technical and administrative equipment. The qualities of students an institution attracts belong also to this category. Some governments have questioned whether there is a link between resources and quality (Church, 1988, 34). For them quality is not just a matter of resources in themselves but of "how" they are used suggesting that process factors have a greater effect. Although it is acknowledged that recent eval- 
uation literature stresses the importance of process factors, in the following conception of quality input factors will also be included. There is no reason to assume that quality control in higher education is something different from quality control as it is practiced in industry which involves a specification of inputs, process monitoring, and end inspection of output (Church, 1988, 30).

By including these factors in a definition of quality, the term encompasses other frequently used terms like efficiency and effectiveness. Efficiency, according to Lindsay $(1981,690)$, refers to the question of how resources are used in the process and effectiveness is defined as the degree to which an institution realizes its goals (Etzioni, 1964).

Because of this broad meaning of quality, critics have argued that only a holistic approach to the assessment of quality can be appropriate. Kuh for example believes that breaking out components that are measurable vitiates the essence of the concept itself (Conrad and Blackburn, 1985, 286). However, for our purposes to assess structures of quality control from a macroperspective, it is necessary to handle the concept of quality in more operational terms. Therefore, a theoretical framework will be proposed in which goals of higher education can be understood and differentiated, without violating the complexity of quality.

In order to arrive at such a framework it may be asked: "goals with respect to what?" Goals may refer to a particular course, an educational program, an institution or the higher education system as a whole. Goals on each of these levels do not necessarily coincide and may differ according to the perspective from which the goal will be considered. For example, a student may be very successful in a particular course, while at the same time the relevance of this course for the educational program can be judged differently. Similarly, a student in art history may have achieved first class exam results, but these results do not automatically give entry credentials to the labor market. From another perspective, an institution may concentrate on certain educational requirements, but at the same time neglect the relevance to societal needs. In each of these examples goals have both an internal and an external dimension, depending on the level of analysis. Figure 1 contains an analytical framework in which a societal, an institutional and an individual level are distinguished. In each cell some goals are indicated which appear quite frequently in various publications on higher education. This overview of goals, however, is far from exhaustive.

These goals which at first glance appear to be harmonious, can in fact be quite incongruent. Goals are ambiguous by nature. Ambiguities appear both between goals at the same level and between goals at different levels. To illustrate this, a few examples will suffice. At the individual level a variety of students' attitudes will come across. Some students will be focused principally on an immediate vocational goal, sensible, if short run, while others will have 


\begin{tabular}{|c|c|c|}
\hline level & Internal & External \\
\hline Societal & $\begin{array}{l}\text { - the amount of education avail- } \\
\text { able } \\
\text { - variety/diversity of the higher } \\
\text { education system (university } \\
\text { and non-university sector) }\end{array}$ & $\begin{array}{l}\text { relation between supply and } \\
\text { demand of graduates } \\
\text { value to the economy in terms } \\
\text { of productivity and inter- } \\
\text { national competitiveness } \\
\text { - scientific and socio-cultural } \\
\text { function of higher education }\end{array}$ \\
\hline Institutional & $\begin{array}{l}\text { - availability of resources; finan- } \\
\text { cial, material, personnel } \\
\text { - student entry qualifications and } \\
\text { admission policy } \\
\text { - internal efficiency }\end{array}$ & $\begin{array}{l}\text { improving students' education- } \\
\text { al and professional qualifi- } \\
\text { cations } \\
\text { - development of independence } \\
\text { of mind and moral autonomy } \\
\text { - institutional responsiveness to } \\
\text { the external environment }\end{array}$ \\
\hline Individual & $\begin{array}{l}\text { contribution of the educational } \\
\text { program to the desired } \\
\text { outcome (value-added) } \\
\text { - learning strategies and pro- } \\
\text { cesses } \\
\text { - availability of course options, } \\
\text { support and advice }\end{array}$ & $\begin{array}{l}\text { - students' program in accor- } \\
\text { dance with employer's needs } \\
\text { - acquiring extracurricular skills; } \\
\text { organizational, communicative, } \\
\text { sports }\end{array}$ \\
\hline
\end{tabular}

Fig. 1. Framework for the classification of goals at three levels of analysis.

their eyes on a more open and indeterminate future. Also, there will be a category of students who want to insure their future life by paying minimal premiums while enjoying their present. As a matter of fact the heterogeneity of the student population has increased considerably over the last ten years.

At other levels goals cannot be pursued independently. The demands of students do not necessarily correspond with the educational program offered by the institution or faculty, neither with demands arising from the labour market. On the other hand, the sometimes problematic relationship between the need for vocational relevance and academic and scientific requirements contains a potential source of tensions (Squires, 1981, 16).

In this framework goals are undifferentiated in terms of importance. There is no hierarchy that places more relevance on certain goals as necessary and/or sufficient conditions for educational quality. Any attempt to assess quality from one perspective unmistakably results in a partial conception of quality. Emphasis on one or just a few goals presupposes the relative importance of some goals and may consequently distort goal-attainment elsewhere in the framework. From a macroperspective all these levels have to be taken into 
account if the balancing demands of quality are to be equally met. Popular slogans used in some circles of quality control like quality being "fitness for purpose" or "fitness for use" do not recognize this multi-dimensional aspect of educational quality.

Of course the question about whose responsibility it is to set such goals remains still to be answered. Which goals are going to be given greatest weight? Before dealing with this question, the quality control system as it actually appears to develop in some West European countries will be considered.

\section{Current structures of quality control}

Although concern for quality in higher education is not new, the present emphasis given to the need for accountability has resulted in the establishment of comprehensive quality control systems throughout the western world. Consequently, many evaluation activities have become visible and the literature on this topic has grown tremendously.

Most of these systems have been broken down in two components, i.e. internal and external evaluation. First of all, it is generally acknowledged that institutions should primarily be responsible for the quality of their education, their research and their other services. Evaluation activities initiated by and carried out by the institution or its substituent parts will presumably contribute to the improvement of educational quality. This internal evaluation is complemented with external evaluation carried out by bodies or groups from without the institution: government, inspectorate, validation- or visiting bodies, peers, employers.

Both internal and external evaluation are included as parts of an integrated quality control system. The relation between the two components has often been understood in terms of a cybernetic model. The evaluation by external groups are considered to be part of the higher education system and their regulatory function derives from being within the system. So Staropoli, the secretary of the French Comite National d'Evaluation, states that the aim of this committee is "less to wield permanent powers of balance or control than to try to develop the academic system's own capacities of evaluation, and hence to permit the whole system to regulate itself"' (Staropoli, 1987, 126). Stated this way, external evaluation follows almost naturally from internal evaluation and tensions between both will likely be limited in scope.

However, to characterize the system, further questions must be addressed concerning the nature and purpose of evaluation. What criteria will be used and why, who initiates the evaluation, who should make evaluative judgements and to whom should these be reported? 
It is quite obvious that the present interest in evaluation is sustained by a number of forces, most notably by financial distress and by the need for accountability. Higher education should demonstrate publicly that resources are being used properly. In most West European countries which predominantly have a centralized higher education system, the government has assigned herself an important role in the process of quality control. This will briefly be illustrated in the light of the situation in the Netherlands.

Since the 1986 University Education Act statutory regulations are provided regarding the ministerial supervision of the quality of education. The Higher Education Inspectorate has been introduced to undertake and coordinate evaluation activities. One of the tasks of the inspectorate is to organize visiting committees and to provide them with administrative support. Besides, the inspectorate has a complementary task to the work done by the visiting committees. That is, the content and methodology of evaluation carried out by these committees will come under the scrutiny of the inspectorate (a practice known as meta-evaluation). Moreover, the work of the visiting committees is not considered to be the only means of assessing quality. All methods and techniques of evaluation are at the inspectorate's disposal, though duplication of work will be avoided. Thus the inspectorate exercises control over the whole evaluation process. It will see all reports from lower levels, set conditions for course approval and generally oversee the monitoring schemes.

Then, the findings of the inspectorate will be reported to the government. According to the governmental paper "Plan for Higher Education and Scientific Research", better known as HOOP, the government "will ask the institutions what conclusions they draw from the inspectorate's report and simultaneously make clear what the conclusions of the minister are" (Ministerie van Onderwijs en Wetenschappen, 1988, 142). Stated this way, a linkage is emphasized between evaluation activities and the information needs of policy-makers who make decisions about financial resources of institutions.

Some general characteristics of this quality control system, which is by no means exclusive to the Netherlands, can be recognized. First, evaluation is carried on basically in a hierarchical way. The government dictates how the quality control process should operate, assigns the tasks of the respective bodies in the process and steers on the basis of measurement. It is likely that the governmental definition of what quality is and how institutional performance should be assessed will weigh quite heavily (Maassen and Van Vught, 1988). This tends to become more and more a central regulation model of quality control.

Second, primacy is given to external evaluation. The system is organized to meet demands of external control. How evaluation should be organized, the procedures, the criteria and norms are settled externally. Although internal and external evaluation are not necessarily opposed, external forces take a greater degree of control. 
Third, evaluation is predominantly summative in nature. Evaluation is focused on measurement of the extent to which goals are attained (productevaluation). The government has a big say in determining goals and establishing priorities between goals. The outcome will be defined accordingly.

\section{Criticism of the regulation model}

It is not surprising that the proposed quality control system has received much criticism. Much of this criticism has been raised about the detailed planning and control mechanisms which are considered as an expression of the tighter linkage between higher education and the state. Getting control over productmanagement matters will restrict the desired institutional autonomy to a considerable extent.

In what follows I shall outline some methodological and substantive weaknesses of the regulation model. In particular, the implications of this model for the conception of quality advocated in the previous section will be considered. What distortions are likely to occur between goals at different levels in the theoretical framework?

\section{Measurement and quantifiability}

Because of the accent on summative evaluation, a regulation model of quality control tends inherently to advocate explicit goals for which there are readily apparent indicators available. Goals which are measurable will have a greater weight than those which are not. This frequent measuring can distort goals on other levels and "tends to encourage overproduction of highly measurable items and neglect of the less measurable ones" (Etzioni, 1964, 9). Even in the United States, where generally speaking a regulation model does not apply, the tide might turn. Among the five powerful trends that are consequently shaping American higher education, Ernest Boyer mentions the legislative demands for measuring the result. He fears that this will end up measuring all things except those that matter most. He notes: "Standards of quality have focused on those aspects that are easiest to count. But these measures do not reveal what colleges and universities actually do" (Boyer, 1987, 11). Educational programs seldom lend themselves to being measured by some quantitative outcomes.

Furthermore, quantitative data are usually presented without much comment about their likely use, nor about their reliability and compilation. The Dutch inspectorate, for instance, has presented a list of over 20 items which are considered to be relevant to the definition of quality. The Inspectorate's 
paper does not address the question regarding the ways in which these items are to be combined or against what yardsticks the items will be judged. Likewise, the Jarrett Report on Efficiency Studies in Universities (1985) suggested a series of performance indicators. As Ball and Halwachi $(1987,399)$ have concluded, the report is quite unclear about which goals the proposed indicators are related to and there is little distinction between measures of input and output. It seems simply taken for granted that there exists a consensus on goals or at least one overriding goal. It can be questioned whether such an emphasis can do justice to the many different goals of higher education or can provide a decent measurement of the most important educational requirements (Bok, 1986).

\section{Relevance}

Another criticism concerns the relevance of data, the extent to which it is considered appropriate for judging quality. Some goals will be highly valued. Others are not because they are not embedded in the research methodology. This may lead to mistaken conclusions. Wright $(1987,14)$ for example criticizes the British government because the rate at which students drop out from courses without obtaining the originally envisaged (or another relevant) qualification is considered as a measure of quality. He shows that movement between courses and institutions, or patterns of intermittent study and movement between different modes of study are simply treated as cases of failure. Such movements, however, might in our framework appear as instances of success at the individual level. Also, at the institutional level the student dropout rate may be acceptable or unacceptable, depending upon, for example, institutional policy regarding entry requirements (Yorke, 1987, 17). The student dropout rate will also be assessed differently from the perspective of the labour market. Employers often show more interests in the product of higher education - highly qualified manpower - and are often more concerned about entry and selection standards. Occasionally they express some hostility to the less selective institutions (Fulton, 1984, 203).

Furthermore, the underlying assumptions of indicators of quality may be questioned. Many of these indicators concern academic research and less teaching. The amount of research conducted by faculty, $\mathrm{PhD}$ completion and number of publications dominate on virtually all evaluation schemes. To what extent some of these indicators such as the number of publications are to be considered as an adequate measurement of the quality of research can seriously be doubted. Moreover, the emphasis given to measure research output seems to suggest either that research is appraised more than teaching or that good research is associated with good teaching. However, this latter view can be 
challenged and there is no evidence to support it. As Williams and Blackstone argue, it is hard to find "solid evidence of any substantial complementarity between the two and there are many arguments which are opposite to the assertion that teaching and research are intimately related" $(1983,84)$. In short, the presumed relevance of indicators outlined in governmental documents is not well founded.

\section{Intended and unintended directions}

The development of a quality control system that is tied in with financial considerations implies that evaluation is placed within a particular framework of quality control. Programs are expected to meet the criteria of government effectiveness. Seen from a behavioral perspective, it is very understandable that internal evaluation will concentrate on those aspects of quality that are valued highest according to the governmental definition of quality. Put differently, evaluation shapes itself in the direction of the governmental definition of quality.

This would not be a problem if the indicators used by the government correspond with a conception of quality on the three levels in the framework outlined before. However, emphasis on certain aspects of quality will have unintended or undesired implications for those aspects which are not included in the governmental approach to quality. For example, success-rates are very frequently applied as an indicator of quality. Consequently, it can be expected that faculty will be encouraged to direct their teaching towards successful completion of exams. Similarly, student credit hours are sometimes used as an indicator of instructional effort and serve as a basis for resource reallocation decisions. If this is the case, faculty and (faculty) administrators of units within the institution tend to adjust their educational programs to generate more of them. Such strategies may run counter to the quality of the educational program.

In the same way, the presumed relationship mentioned before between research and teaching may have deleterious consequences for the latter. As Elton notes, the fact that governmental bodies appraise research, but not teaching, is beginning to result in a shift of effort in universities from teaching to research. Whether the result has been an improvement of research is doubtful, since most of the extra effort seems to have gone into chasing research funds (Elton, 1988, 382). The priority given to research above teaching supports the traditional value system which prevails in universities. In decisions about academic promotion and tenure, teaching qualifications are seldom required, whereas in primary and secondary education this is a standard requirement. Those lowest in the academic hierarchy, frequently the less 
experienced graduate students, are deployed to teach. In short, a predominant use of research indicators reveals the higher status given to research and implies that teaching will continue to be poorly endowed.

As far as the societal level is concerned, a strong unilateral orientation of institutions towards the government might have implications for diversity and variety of the higher education system. This raises the problem of what Riesman, Trow, Clark, Birnbaum and others have referred to as "institutional homogenization". That is the increasing tendency for institutions to follow national rather than regional models. Most national evaluation committees and inspectorates are inclined to extend their investigations to what Staropoli calls "all public, scientific, cultural and professional institutions" (Staropoli, 1987, 128).

Although many governments, among them the Dutch government, have apparently maintained a binary policy as a crude guarantor of institutional diversity, quality control cuts across the categorial distinctions between the university and the non-university sector. However, more important questions are not addressed, which concern those of the possibly different (but not necessarily higher or lower) standards appropriate to different institutions, and of the range of activities that could or should make up a system of higher education (Moodie, 1988, 10). Here, a basic dilemma arises. A quality control system which requires certain uniform standards and measurements is contrary to the increasingly felt need for diversity in education, flexible responsiveness and a reasonable amount of institutional initiative and autonomy. This institutional diversity is being threatened by imperatives built into the system which drives institutions in the direction of similar responses to common problems. Institutions tend to become more alike.

\section{Assessment of quality: within and without}

In the preceding section a regulation model of quality control has been criticized for several methodological reasons. These criticisms boil down to the fact that goals are mainly viewed from the governmental frame of reference. Quality is defined as meeting the governmental requirements and evaluation is consequently more oriented towards the control and decision-making process at the macro-level rather than towards the improvement of teaching and research. Quality control is predominantly carried out by means of centrally generated uniform standards which tend to function as yardsticks along which institutions or parts of it, are judged for purposes of funding or resource allocation. A focus on discipline-based evaluation facilitates this process in which disciplines at different institutions can be compared and ranked, and provides a standard of performance which may or may not be achieved. Procedures are often mandated, in an effort to attain uniformity of outcomes. 
Quality measurement with emphasis upon uniform standards as conceived in this regulation model also allows for a finer targeting of currently advocated systems of financial incentives, such as performance-funding and missionbudgets, to promote certain reforms and to achieve certain goals. Such a quality control system has explicitly political overtones. It is designed to yield conclusions about the worth of higher education and in doing so, is intended to affect the allocation of resources. Consequently, evaluation results enter the political arena. There, as Weiss $(1987,48)$ states, evaluative evidence of program outcomes has to compete for attention with other factors that carry weight in the political process and is subject to political opportunism. It is very doubtful whether on that level there exists an evaluation capacity, that is, the application of rational instruments on behalf of the planning and decision making process.

It is clear, then, that a recognition of quality from one perspective may erode institutional autonomy to a considerable extent. Quality has become subject to much regulation. This takes on the status of a regulated industry of quality control.

In avoiding these harmful consequences a major shift should be considered from a regulation model towards a quality control system which does more justice to the variety and complexity of the higher educational system. Such a system leaves room to a diversity of beliefs of various groups that are involved or associated with the institutions.

A case for institutional autonomy arises from the starting point that institutions have to decide to which goals they will give greatest weight. This implies that quality will be assessed specifically with reference to the goals of a particular institution or the target academic program. For the sake of maintaining diversity, not all institutions should necessarily pursue the same goals. For instance, should an institution concentrate on those students who are most promising and responsive or should it have a more egalitarian dedication? Should an institution be focused on research or should it put quite explicitly undergraduate teaching above research?

Criteria should be developed with reference to these institutional goals. A criterion that "every lecturer should achieve a specified number of such publications each year" is not appropriate to assess the quality of an institution which emphasizes teaching goals. On the contrary, there are reasons why students might be better taught in institutions which are not distracted by claims that academic research is the main priority of their teachers. Similarly, laboratory equipment or the amount of copies of basic tests in the library should be judged in the context of particular goals. Thus, criteria for quality may vary according to the goal of a specific course, program or institution.

The view that institutions should be able to shape and pursue their own objectives implies that evaluation should be initiated as an internal process. 
However, this does not exclude any necessity of external evaluation. On the contrary, without external evaluation there would be little internal evaluation or self-evaluation attempts to effect institutional improvement, as the American experience teaches (Cook, 1988, 7). But this evaluation is not externally imposed by one outside agency, but is arranged by the institutions themselves.

In such a model a specific sequence of internal followed by external evaluation exists which allows the institution time to meet or plan for the correction of deficiencies. According to Kells and Van Vught (1988) such an institution-centered model of quality control, in which ongoing collaborative studies and institutional self-study processes are the main elements, will be a guarantee for enhancing quality.

The results of this internal evaluation should be externally validated and legitimized. Moreover, incentives from outside are necessary to meet externally defined goals at both societal, institutional and individual level. For this purpose a system of accreditation or peer review may function. Furthermore, hearings may be held at which different groups can express their interests and assert their needs, which are not always mutually reconcilable. In such a situation the role of the government is limited to the encouragement of immediate intrinsic mechanisms through which relevant groups may exert their influence.

Adherents of a regulation model often argue that government represents all interests equally well, including those of employers. However, a distinction should be made between efforts of institutions to show the government that they operate in accordance with employers' needs on the one hand and actual efforts to do so on the other hand. For example, Dutch universities have in recent years been eager to profit from financial incentives emanating from government, particularly in the sphere of information sciences. This has given the application and short-term activities a disproportionate amount of attention at the expense of scientific development. Although it is assumed that this development meets the demands and preferences of employers, the latter have on several occasions expressed their concern. Employers are recognizing the shortcomings of an excessive emphasis on narrow technical skills in employee development. As Lynton and Elman $(1987,112)$ state, "the larger corporations in particular are increasingly realizing that if they want their employees to have the insight and ability to weigh alternatives, then they need to provide a longer-range and broader educational approach". Recently a group of 35 representatives of Dutch industry unanimously came to the conclusion that:

universities are responsible for their educational programs and should remain so. Simultaneously, they must take into account the wishes and needs of the labour market without following these blindly. Not only because the private sector is unable to specify its needs but mainly to prevent lack of variety. The private sector's wishes must be "weighed" against the universities' own tasks 
and interests. This view appeared to be generally accepted during the conference (VSNU, 1988, 4).

In other words, institutions themselves have to make a careful determination of which tasks are appropriate to their general goals and which are not. Institutions are dealing with different environments and with different processes and strategies. This demands a quality control system which is more geared to these specific circumstances. If judged in the light of our theoretical framework, such an approach permits variety, flexibility and willingness to innovate. As Williams and Blackstone have contended:

Gross errors are more likely to be avoided, and the occasional brilliant insight made, when many different flowers are blooming. Error or misjudgement or inertia in some institutions may be more than compensated for by the benefits obtained from the successful ones $(1983,66)$.

\section{Concluding comments}

The principal thesis put forward in this article is that the quality control systems currently being developed in countries like the Netherlands, France and England tend in the direction of a model tightly controlled by the central government. It is argued here why a shift towards another, more intrinsic model of quality control is desirable. In such a model the quality of higher education is not judged in terms of criteria imposed from the outside by one centre of power. Rather, quality results from balancing the different interests and different perspectives of all those who have an interest in the quality of education. Consumers like students and employers of graduates are bound to have their own legitimate concerns.

It can be expected that goals will be achieved at the societal, institutional and individual level. At the societal level more variety and flexibility will be maintained. At the institutional level, people within the institutions are encouraged to enhance the quality of education. At the individual level students may assess the quality of teaching, a practice which is fairly uncommon in present higher education. Particularly where there are less curricular requirements, their influence may increase considerably.

The integrity of the evaluator resides in providing insight into the interests and motivations of all actors within and without higher education and then doing a fair and balanced job of assessing the quality of higher education. In that sense evaluation serves the information needs of the (potential) consumers. 


\section{Acknowledgements}

Special thanks are due to my colleagues Peter A. M. Maassen and Peter J. M. Weusthof for the development of several views put forward in this paper and to all those at the Forum who stimulated me with their comments.

\section{Note}

1. Revised version of a paper presented at the Tenth Forum of the European Association for Institutional Research, University of Bergen, Norway, August 1988.

\section{References}

Ball, Ch., Essays in Higher Education, The Society for Research into Higher Education \& NFER-Nelson, Surrey, Guildford, 1985.

Ball, R. \& J. Halwachi, Performance indicators in higher education, in: Higher Education, 16, 1987, 393-405.

Barnett, R. A., The maintenance of quality in the public sector of UK higher education, in: Higher Education, 16, 1987, p. 279-301.

Bergquist, W. H. \& J. L. Armstrong, Planning Effectively for Educational Quality, Jossey-Bass Publishers, San Francisco, 1986.

Birnbaum, R., Maintaining Diversity in Higher Education, Jossey-Bass, London, 1983.

Bok, D., Higher Learning, Cambridge, Harvard University Press, 1986.

Boyer, E. L., American higher education: the tide and the undertow, in: International Journal of Institutional Management in Higher Education, 1987, vol. 11, no. 1, p. 5-12.

Conrad, C. F. \& R. T. Blackburn, Program quality in higher education, in: Higher Education, Handbook of Theory and Practice, vol. 1, Agathon Press Inc., New York, 1985, p. 283-308.

Cook, C. M., Internal and External Evaluation: Reflections on the American Experience, paper presented at the International Conference on Quality Assessment in Higher Education, Noordwijk, The Netherlands, May 1988.

Church, C. H., The qualities of validation, in: Studies in Higher Education, vol. 13, no. 1, 1988, p. $27-44$.

Elton, L., Accountability in higher education: The danger of unintended consequences, in: Higher Education, 17, 1988, 377-391.

Etzioni, A., Modern Organizations, London, Engelwood Cliffs, 1964.

Fulton, O., Needs, expectations and responses: new pressures on higher education, in: Higher Education, 13, 1984, 193-223.

Higher Education Inspectorate, paper delivered at the International Conference on Quality Assessment in Higher Education, Noordwijk, The Netherlands, May 1988.

Kells, H. R. \& F. A. van Vught, Theoretical and practical aspects of a self-regulation and quality control system for Dutch higher education, in: Tijdschrift voor Hoger Onderwijs, vol. 6, no. 1,1988, p. $15-21$.

Lynton, E. A. \& S. E. Elman, New Priorities for the University, Jossey-Bass Publishers, 1987.

Maassen, P. A. M. \& F. A. van Vught, An intriguing Janushead, The two faces of the new governmental strategy towards higher education in the Netherlands, in: European Journal of Education, vol. 23, no. 1/2, 1988, p. 65-77.

Ministerie van Onderwijs \& Wetenschappen, Hoger Onderwijs en Onderzoekplan (HOOP), Zoetermeer, 1988. 
Moodie, G. C., The debates about higher education quality in Britain and the USA, in: Studies in Higher Education, vol. 13, no. 1, 1988, p. 5-12.

Lindsay, A., Assessing institutional performance in higher education: a managerial perspective, in: Higher Education, 10, 1981, p. 687-706.

Neave, G., Editorial, in: European Journal of Education, vol. 22, no. 2, 1987, p. 121-123.

Perry, P., Accountability and inspection in higher education, in: Higher Education Quarterly, vol. 41, no. 4, 1987, p. 344-354.

Pirsig, R. M., Zen and the Art of Motorcycle Maintenance, Corgi-books, 1974.

Scheerens, J., Het Evaluerend Vermogen van Onderwijsorganisaties, Enschede, Rede Universiteit Twente, 1987.

Squires, G., The Reform of Studies in Higher Education, OECD policies for higher education in the 80's, Paris, 1981.

Staropoli, A., The Comité National d'Evaluation: preliminary results of a French experiment, in: European Journal of Education, vol. 22, nr. 2, 1987, p. 123-132.

VSNU, Over Eerste-Fase Opgeleiden Wetenschappelijk Onderwijs, Samenvattend verslag van een werkconferentie, 1988.

Weert, E. de, \& P. J. M. Weusthof, Kwaliteit centraal gestuurd? Het kwaliteitsbewakingssysteem bezien vanuit een driedimensionaal perspectief, in: R. J. Bijleveld \& R.J.G.M. Florax (eds.), Laissez-Faire in het Hoger Onderwijs?, Lemma, 1988, p. 154-183.

Weiss, C. H., Where politics and evaluation research meet, in: D. J. Palumbo (ed.), The Politics of Program Evaluation, Sage publication, Newbury Park, 1987, p. 47-72.

Williams, G. \& T. Blackstone, Response to Adversity, Society for research into higher education, Guildford, Surrey, 1983.

Wright, P. W. G., Who Defines Quality in Higher Education? Reflections on the influence of professional power on conceptions of quality in English higher education. Paper presented at the Ninth European AIR-Forum, Enschede, The Netherlands, 1987.

Yorke, D. M., Indicators of institutional achievement: some theoretical and empirical considerations, in: Higher Education, 16, 1987, p. 3-20. 